\title{
Auxiliary Power Supply Based On A Modular Isop Flyback Configuration With Very High Input Voltage
}

\author{
Alberto Rodriguez, Maria R. Rogina, Mariam Saeed, Diego G. Lamar, Manuel Arias, Mario Lopez and Fernando Briz \\ Department of Electrical Engineering. University of Oviedo. \\ Campus de Viesques s/n, 33204. Gijon. Spain \\ rodriguezalberto@uniovi.es
}

\begin{abstract}
This paper proposes a Flyback-based Input-Series Output-Parallel (ISOP) Auxiliary Power Supply (APS), intended to feed the control system of the cells of a Solid-State Transformer (SST). The SST topology is based on a modular Multiport Multilevel Converter (MMC). Energization of the cells auxiliary circuitry is not trivial due to the high voltages involved (tens of $\mathbf{k V}$ for the electric power distribution system), most of the commercially available control and driving circuitry not being usable due to the isolation requirements. It is possible to energize the control circuitry from an APS, connected to the cell capacitor voltage. However, in the SST under consideration, cells target DC voltage is in the range of $1.5 \mathrm{kV}$ to $2.5 \mathrm{kV}$. Design of an APS capable of feeding the auxiliary circuitry from such high voltage and the required isolation is not trivial. A modular APS using autonomous Flyback converters in Continuous Conduction Mode (CCM) and based on commercial $\mathrm{AC}$ adapters is proposed in this paper. The solution is scalable and therefore applicable to cells with larger DC voltages.
\end{abstract}

Keywords - ISOP, High voltage, APS, DC/DC converter.

\section{INTRODUCTION}

Distributed generation has become a necessity due to many economic, environmental and technical reasons. With the increasing energy demand worldwide, energy efficiency has become a crucial consideration, the term "Microgrid" has become very common and the increasing energy demand is intended to be fed by distributed energy resources such as wind and solar installations [1]. The need for bidirectional as well as high-voltage and high-power conversion applications are growing fast to interconnect these new grids with the main grid and increase their reliability leading to the emergence of Flexible AC Transmission Systems (FACTS), High-Voltage DC (HVDC) and Solid-State Transformer (SST).

Conventional Line-Frequency Transformers (LFT) are a key element in the transmission system. While they are cheap and a reliable and a well-established technology, they have limitations regarding functionalities demanded by the power system operator, such as harmonics, reactive power and imbalances compensation, and power flow control. Also, their efficiency can be compromised when operating with low load levels. Solid State Transformers (SSTs) are envisioned as semiconductor based alternative to LFT. SSTs use power converters with fast switching devices, enabling a significant reduction of the volume and weight of the core material. Additionally, they are able to provide advanced functionalities such as power flow control, as well as reactive power, harmonics and imbalances compensation [2]-[5]. Generally speaking, the SST is expected to beat the LFT in terms of power density and much superior functionalities, but it would be inferior in terms of cost, efficiency (full load) and reliability.

The concept of SST has been discussed since 1970 [6]. The SST topology derived from a Multiport Multilevel Converter (MMC) has drawn great attention in the SST research field [7]. The connection of a Dual Active Bridge (DAB) [8]-[11] to each cell capacitor of the MMC provides the capability to transfer power between the primary and the secondary with galvanic isolation [12], [13]. A simplified diagram of the MMC based SST topology is shown in Fig. 1.

An Auxiliary Power Supply (APS) providing a low-voltage (i.e. $24 / 15 / 12 \mathrm{~V}$ ) and low power (in the range of $30-50 \mathrm{~W}$ ) is necessary to feed the control circuitry of each cell (including DAB and MMC cells). Although the proposed APS is intended to feed the control circuitry of a SST, it could be also applied in different modular multilevel topologies.

Actual DC bus voltage of multilevel converters is in the range of $800 \mathrm{~V}-1.5 \mathrm{kV}$, mainly due to the maximum voltage withstood by the switches available in the market (Silicon IGBTs or even SiC MOSFETs). However, recent developments of $10-15 \mathrm{kV} \mathrm{SiC} \mathrm{MOSFETs} \mathrm{and} \mathrm{IGBTs} \mathrm{have} \mathrm{enhanced} \mathrm{the} \mathrm{scope}$ of $\mathrm{dc}$ bus voltages of $7 \mathrm{kV}$ and above [14]. In order to address the increase of the voltage in DC links, a modular APS is proposed in this paper. Thanks to the modularity, the APS can be used in cells with high voltage DC links by increasing the number of modules.

The main requirements of the APS for the modular multilevel topologies can be summarized in two:

- On one hand, isolation between primary and secondary of the APS is needed. Moreover, the input of the APS is the DC bus voltage of the cell, usually over $1 \mathrm{kV}$ and probably higher in the future. Due to the high input voltage of the DC bus, in addition to the high isolation required, the conversion ratio of the APS is also very high, usually higher than 100 .

- On the other hand, the DC bus voltage of each cell is not referred to ground. The DC link of several cells can be dozens of $\mathrm{kV}$ over the global reference. Consequently, the control circuitry of all the stacked MMC-DAB cells cannot be connected to the same DC voltage supply, due to very high isolation requirements, as a relatively large number of cells need to be piled-up to provide the required HV AC side voltage. 


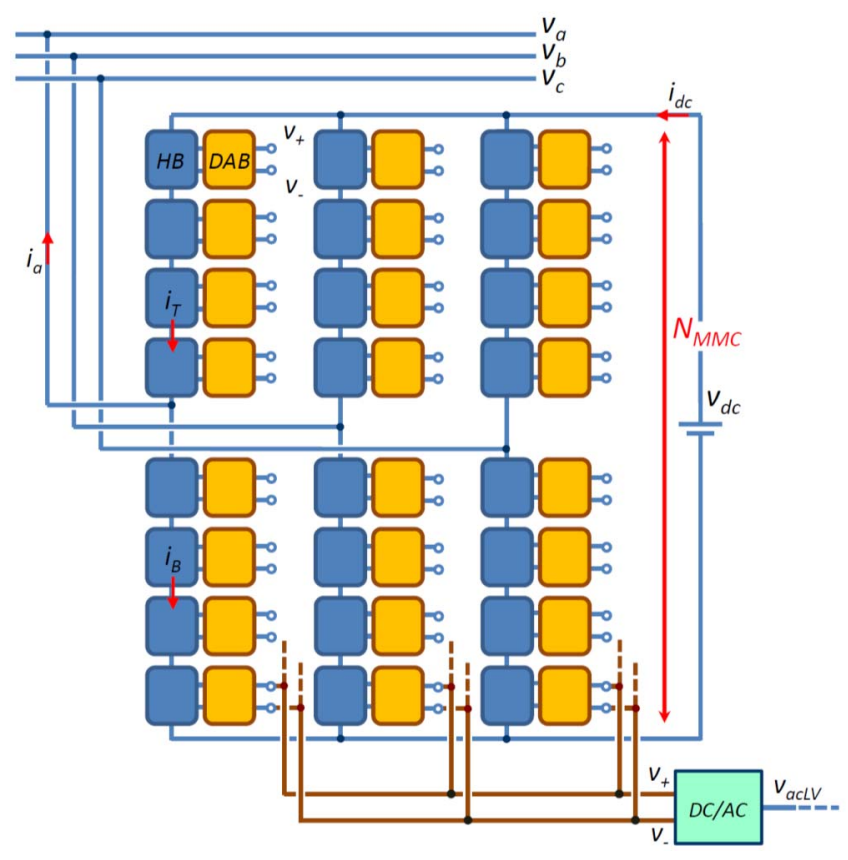

(a)

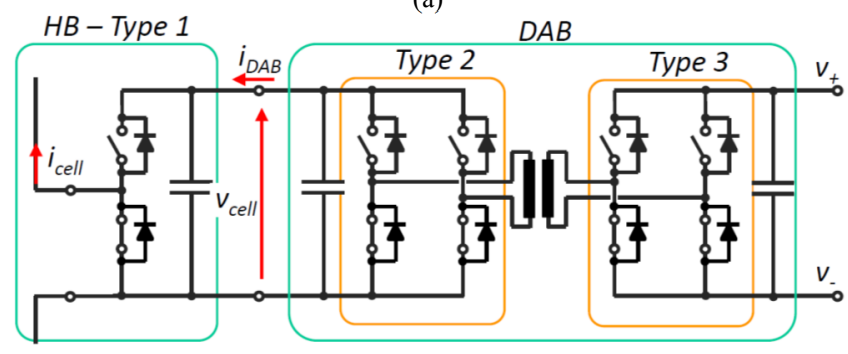

(b)

Fig. 1. (a) Representation of the proposed SST topology. (b) MMC cell and DAB for each cell of the MMC-based SST. Cell capacitor voltage $\left(v_{c e l l}\right)$ is used to feed the proposed APS.

As an example, the particular application of a SST connecting two AC grids of $24 \mathrm{kV}$ and $400 \mathrm{~V}$ respectively is analyzed in this paper (one of the configurations being considered within the SPEED project [15]). A cell voltage $v_{\text {cell }}=$ $1.4 \mathrm{kV}$ was selected, which is equal to the DAB voltage in the $\mathrm{HV}$ side and the input voltage of the APS proposed in this paper. The DC link voltage in the LV side is $750 \mathrm{~V}$. The DABs are designed for rated power of $10 \mathrm{~kW}$. Commercially available APSs do not provide the required isolation for this kind of application. The solution proposed in this paper integrates a modular APS in each MMC-DAB cell. A modular Input-Series Output-Parallel (ISOP) structure based on a Flyback topology was chosen to accomplish with the $\mathrm{HV}$ at its input and low output power requirements [16].

This paper is organized as follows. In Section I, the main application and requirements of the APS under development has been mentioned. In Section II, the analytical equations of the proposed Flyback-Based Modular ISOP converter are stated and simulation results are presented. In Section III, experimental results using two different prototypes are shown. Finally, conclusions are drawn in Section IV.

\section{ANALYSIS Of THE FlybaCK-BASED MOdULAR ISOP CONVERTER}

To feed the control circuitry of each cell (including DAB and MMC cells) of a SST topology fulfilling the previously detailed isolation requirements, an APS providing a low voltage and low output power from the cell capacitor voltage $\left(v_{\text {cell }}\right)$ is proposed.

Different solutions are proposed in the literature. For example, two quite expensive and complex methods are provided for auxiliary power supply for SST in [17]. Also, resonant topologies, as series half bridge structure, and threelevel structure are analyzed in [18] and [19], but they are limited when the DC bus voltage and consequently their input voltage is increased. To get over the actual increase in the DC bus voltage level, ISOP structures are evaluated in [20], which can be used for very high voltage thanks to the possibility of increasing the number of modules connected in series in the input.

In this paper, an autonomous, simple and cheap Flybackbased ISOP converter is proposed and analyzed. The maximum input voltage of the converter can be easily increased, using Flyback converters, thanks to their autonomy. In Section III two different prototypes are proposed to validate the modular concept. Four Flybacks converters connecting their inputs in series and their outputs in parallel (ISOP configuration) compose the definitive APS prototype intended to feed the control circuitry of the SST. This configuration is used as an example to validate the proper operation of the proposed structure with an input voltage of $1400 \mathrm{~V}$ (the voltage at the MMC cell, $v_{\text {cell }}$ ) and an output voltage of $15 \mathrm{~V}$. It is important to say that each Flyback operates in open loop configuration. All the simulation and analytical results presented in this section have been obtained using the configuration and specifications previously mentioned.

The main challenge faced by the ISOP configuration is to achieve a balanced Input Voltage Sharing (IVS) and Output Current Sharing (OCS). Flyback converters are proposed for each module because they are cheap, reliable, use a simple topology, provide galvanic isolation and have a high conversion ratio. In fact, low power commercial $\mathrm{AC} / \mathrm{DC}$ adapters available on large scale can be adjusted to meet the requirements. To avoid additional control circuitry (mainly the feedback loop) and to obtain a load-independent output voltage, open loop and CCM operation are selected. The unregulated output voltage will be determined by a fixed duty cycle, the turn ratio of the transformer and the input voltage.

Analytical study of the converter topology to proof the IVS and OCS concept will be performed. Simulations of the switching and averaged model (Fig. 2) also will be performed to confirm the correctness of the model.

\section{A. Analytical expressions of the Flyback-based ISOP converter}

Traditionally, in an ISOP configuration with paralleled outputs, Discontinuous Conduction Mode (DCM) operation is preferred, as in this mode of operation the converter works as a current source and it is easy to parallelize their outputs [21], [22]. The main disadvantage of the DCM is that the ratio between input and output voltage depends on the load. In addition, rms currents and conduction losses are higher. On the other hand, 
with CCM, the output voltage of a Flyback is constant for a given input voltage and a duty cycle, allowing open loop operation if the input voltage is controlled (as a theoretical DC transformer, i.e. a DCX).

To validate the operation of Flyback modules in CCM in an ISOP configuration and an acceptable IVS and OCS, the input voltage and output current equations are analyzed. Since the average inductor voltage over one switching cycle should be zero [23], the input voltage is given by:

$$
V_{\text {in }}=\frac{V_{\text {out }} \cdot n \cdot(1-d)}{d}
$$

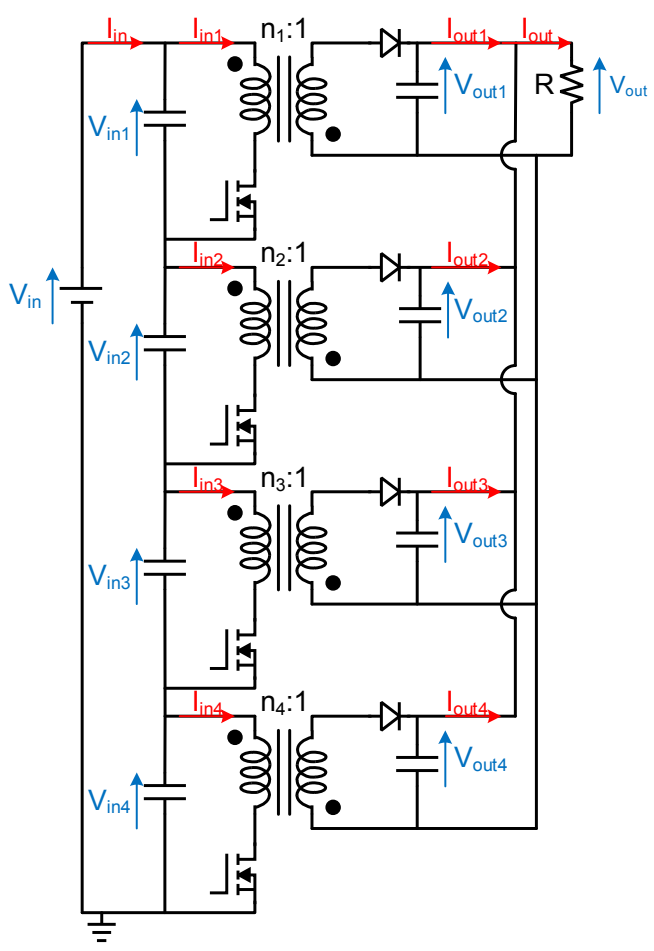

(a)

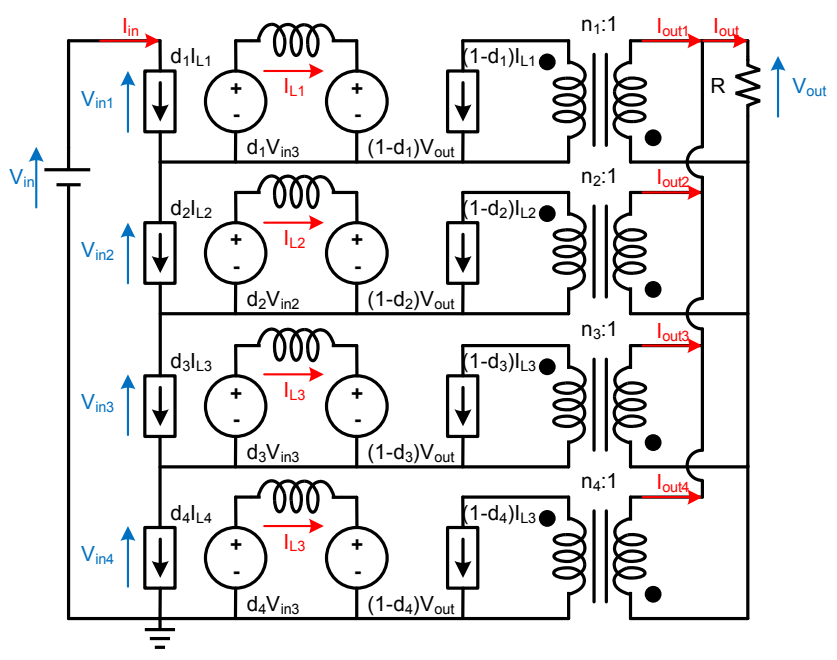

(b)

Fig. 2. Simulation models: (a) switching and (b) averaged. being $n$ the transformer turns ratio, $V_{\text {in }}$ the input voltage, $V_{\text {out }}$ the output voltage and $d$ the duty cycle. Generalizing the equation for the ISOP topology, where the output voltage is the same in all converters, and using $i$ as the number of the module, the input voltage of each module is given by:

$$
V_{\text {in }}=\frac{V_{\text {out }} \cdot n_{i} \cdot\left(1-d_{i}\right)}{d_{i}} .
$$

To estimate the input voltage of each converter in an ISOP configuration it is useful to define the parameter $N_{i}$ (used as a figure of merit to validate IVS and OCS), given by:

$$
N_{i}=\frac{d_{i}}{n_{i} \cdot\left(1-d_{i}\right)}
$$

Using (3) in (2), the input voltage can be calculated by:

$$
V_{i n_{i}}=\frac{V_{\text {out }}}{N_{i}} \text {. }
$$

The output current of each Flyback converter is given by:

$$
I_{\text {out }_{i}}=\left(1-d_{i}\right) I_{L_{i}} n_{i},
$$

being $I_{L i}$ the average current through the Flyback's magnetizing inductance. Due to the ISOP configuration, and considering zero the average current through each input capacitor over one switching cycle, the input current of the ISOP converter is the input current of each Flyback converter, $I_{i n}=I_{i n_{i}}$. The average current through each magnetizing inductance can be obtained by:

$$
I_{L_{i}}=\frac{I_{\text {in }}}{d_{i}} .
$$

Assuming there are no converter losses $P_{\text {in }}=P_{\text {out }}$, the input current can be written as:

$$
I_{\text {in }}=\frac{V_{\text {out }}{ }^{2} / R}{V_{\text {in }}},
$$

where $R$ is the value of the load.

Finally, the output current of each module can be defined by:

$$
I_{\text {out }}=\frac{V_{\text {out }}{ }^{2} \cdot n_{i} \cdot\left(1-d_{i}\right)}{R \cdot V_{\text {in }} \cdot d_{i}}
$$

It is important to say that commercial transformers can guarantee similar turn ratio $(n)$ in all the Flyback converters with an acceptable tolerance $( \pm 10 \%$ for resistance and inductance values and $\pm 1-2 \%$ for turn ratio [24]). Consequently, taking into account (2) and (8) both depending on $d_{i}$ and $n_{i}$, IVS and OCS can be easily achieved by only controlling $\mathrm{d}_{\mathrm{i}}$.

\section{B. Simulation results (switching and averaged model)}

Switching and averaged models of the Flyback-based ISOP configuration converter have been simulated using LTSpice (Fig. 2). TABLE I shows the main specifications of the Flyback converters that composes the ISOP converter used for the simulations. These specifications match with the scenario previously mentioned (i.e. SPEED project). It is seen that some dispersion among converters (based on the differences observed in the developed prototypes that will be described in Section III.A) has been included. The value of the parameter $N$ (determine by $d$ and $n$ ) is also included. The similarity of $N_{i}$ in all the Flyback converters determines the proper IVS and OCS.

TABLE II shows the results obtained using the switching and averaged simulation (Fig. 3) and the analytical model. Good agreement between simulation and analytical results and good 
OCS and IVS exist. Some differences arise between simulations and results because model of components closer to real behavior have been used in the switching simulation, while in the average simulation all the components are ideal. As can be seen the input voltage in Flyback 3 is considerably lower, mainly due to its higher value of $N$. In Section III, TABLE IV shows that Flyback 3 also gives the highest experimental output voltage (as can be predicted using (4)).

TABLE I. SPECIFICATIONS OF THE CUSTOMIZED FLYBACK CONVERTERS THAT COMPOSE THE ISOP CONFIGURATION

\begin{tabular}{r|c|c|c|c} 
Flyback & $\mathbf{1}$ & $\mathbf{2}$ & $\mathbf{3}$ & $\mathbf{4}$ \\
\hline $\mathbf{L}(\mathbf{m H})$ & 20.838 & 20.28 & 25.503 & 21.195 \\
\hline $\mathbf{d}$ & 0.295 & 0.296 & 0.312 & 0.297 \\
\hline $\mathbf{n}$ & 9.89 & 9.88 & 10.31 & 9.84 \\
\hline $\mathbf{N}$ & 0.0423 & 0.0425 & 0.044 & 0.0429 \\
\hline $\mathbf{f}_{\text {sw }}(\mathbf{k H z})$ & 100 & 100 & 100 & 100
\end{tabular}

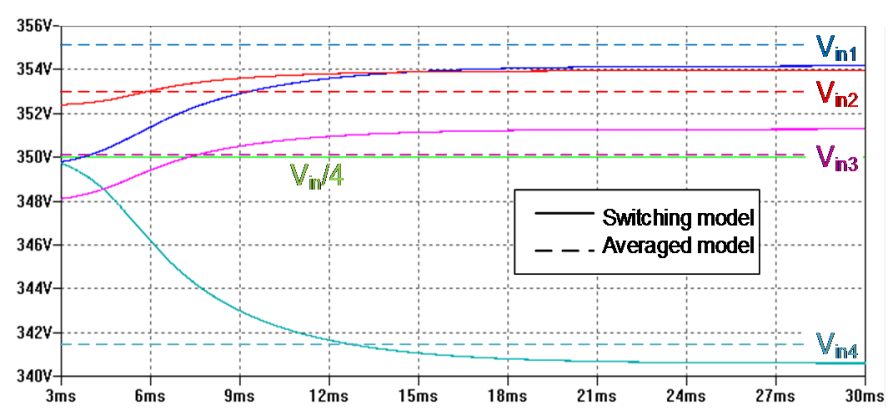

Fig. 3. Switching and averaged simulation models results.

TABLE II. SimULATION AND ANALITICAL MODELS RESULTS

Common specifications

\begin{tabular}{r|c|c|c|c}
\multicolumn{6}{c}{ Common specifications } \\
\hline $\mathbf{V}_{\text {in }}(\mathbf{V})$ & 1400 & & $\mathbf{R}(\boldsymbol{\Omega})$ & 6 \\
\hline \multicolumn{5}{|c}{ Switching model results } \\
\hline $\mathbf{I}_{\text {in }}(\mathbf{m A})$ & 30.5 & & $\mathbf{P}_{\text {in }}(\mathbf{W})$ & 42.7 \\
\hline $\mathbf{V}_{\text {out }}(\mathbf{V})$ & 15.04 & & $\mathbf{P}_{\text {out }}(\mathbf{W})$ & 37.69 \\
\hline Flyback $_{\text {ybar }}$ & $\mathbf{1}$ & $\mathbf{2}$ & $\mathbf{3}$ & $\mathbf{4}$ \\
\hline $\mathbf{V}_{\text {in }}(\mathbf{V})$ & 354.17 & 353.96 & 340.59 & 351.28 \\
\hline $\mathbf{I}_{\text {out }}(\mathbf{A})$ & 0.635 & 0.634 & 0.607 & 0.630 \\
\hline
\end{tabular}

Averaged model results

\begin{tabular}{r|c|c|c|c}
\hline \multicolumn{5}{|c}{ Averaged model results } \\
\hline $\mathbf{I}_{\text {in }}(\mathbf{m A})$ & 26.9 & & $\mathbf{P}_{\text {in }}(\mathbf{W})$ & 37.66 \\
\hline $\mathbf{V}_{\text {out }}(\mathbf{V})$ & 15.03 & & $\mathbf{P}_{\text {out }}(\mathbf{W})$ & 37.64 \\
\hline Flyback & $\mathbf{1}$ & $\mathbf{2}$ & $\mathbf{3}$ & $\mathbf{4}$ \\
\hline $\mathbf{V}_{\text {in }}(\mathbf{V})$ & 355.19 & 353.13 & 341.66 & 350.02 \\
\hline $\mathbf{I}_{\text {out }}(\mathbf{A})$ & 0.635 & 0.632 & 0.611 & 0.626 \\
\hline \multicolumn{5}{|c}{ Analytical model results } \\
\hline $\mathbf{V}_{\text {in }}(\mathbf{V})$ & 355.38 & 353.34 & 341.57 & 350.24 \\
\hline $\mathbf{I}_{\text {out }}(\mathbf{A})$ & 0.636 & 0.632 & 0.611 & 0.627
\end{tabular}

\section{EXPERIMENTAL PROTYPES AND EXPERIMENTAL RESUlTS}

To develop the Flyback-based ISOP configuration converter two different approach have been developed in order to demonstrate that this idea is easily implemented on commercially available structures that can be modified without difficulty as they are well known.

On one hand, a commercial $\mathrm{AC}$ adapter is used to obtain individual Flyback converters. These AC adapters usually include Flyback converters working in DCM and closed loop, and consequently some modifications have been introduced to achieve the open loop operation mode in CCM. As an example, three of these converters are used to obtain a Flyback-based ISOP converter with an input voltage $\left(V_{\text {in }}\right)$ of $600 \mathrm{~V}$. This value was selected because each of the three converters were modified to work in open loop in CCM with an input voltage of $200 \mathrm{~V}$ each.

On the other hand, customized Flyback converters have been developed, mainly to increase the input voltage of each individual Flyback $\left(V_{i n i}\right)$ and their range of operation in CCM. With four of these customized converters, a $1500 \mathrm{~V}$ input voltage Flyback-based ISOP converter is developed and tested.

Obviously, in both cases, thanks to the autonomy of each Flyback converter, $V_{\text {in }}$ can be easily increased by connecting more Flyback converters.

\section{A. Using a modified commercial AC adapter \\ 1) Individual Flyback converter}

Initially, individual Flyback converters were obtained by introducing some modifications to a commercial AC adapter with an integrated current mode PWM control IC (OB2236). The input rectifier was removed, being the DC input voltage directly applied to the input capacitor. The OB2236 IC is selfpowered from its input voltage $\left(V_{i n i}\right)$. The closed loop circuitry used to regulate the output voltage of the AC adapter is removed and the converter is controlled in open loop applying a constant voltage to the feedback input pin of the IC. The operation in CCM is obtained by increasing the switching frequency.

The specified commercial AC adapter (Fig. 4) is selected to guarantee similar performance among them, however some differences exists due to the tolerances in the manufacturing process. The input voltage of each Flyback was limited to $200 \mathrm{~V}$ because the converter is not optimized for the selected switching frequency and the aim is not entering in DCM.

\section{2) Flyback-based ISOP converter}

A 50W prototype has been built using three Flyback converters. As has been previously mentioned, the total input voltage is $600 \mathrm{~V}$. Fig. 5 shows the experimental waveforms of the total input voltage $\left(V_{\text {in }}\right)$ and the input voltage distribution in each Flyback converter $\left(V_{i n i}\right)$. TABLE III shows the input voltage and output current distribution. It is seen that the input voltage and the output current of Flyback 1 are considerably lower due to its lower turn ratio, which implies a higher value of $N_{i}$. The experimental results are in good agreement with the analytical and simulation results. The small differences are mainly due to the low efficiency $(<75 \%)$ of each Flyback converter. 


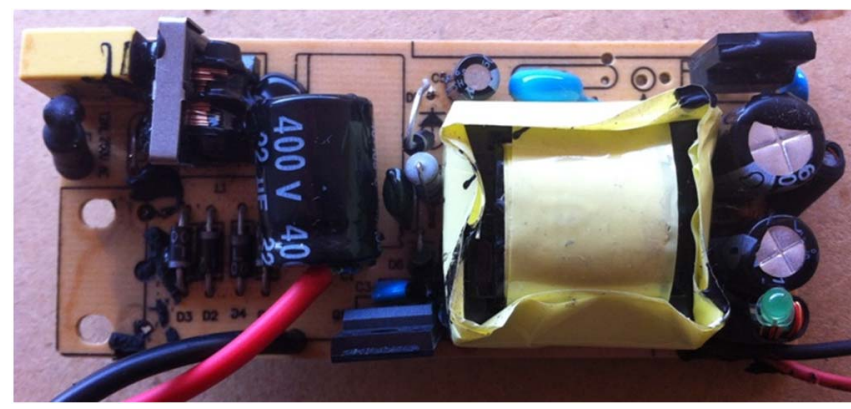

Fig. 4. Commercial Flyback adapted for the ISOP modular converter.

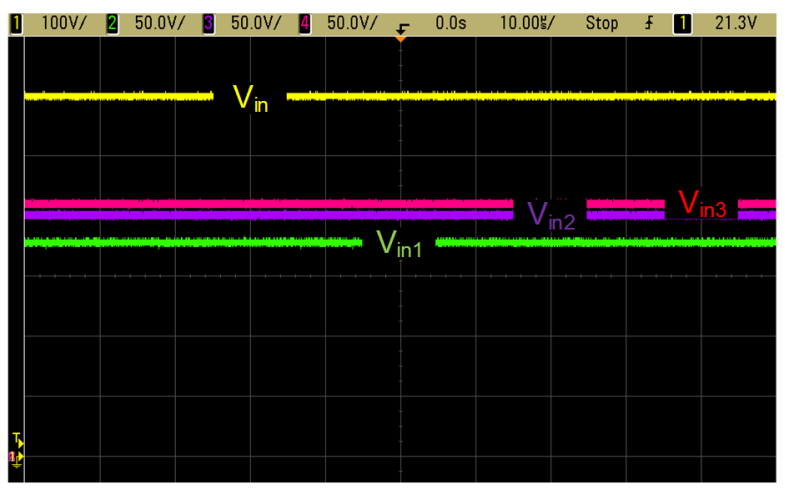

Fig. 5. Experimental waveforms of the input voltage distribution.

TABLE III. IVS AND OCS EXPERIMENTAL AND ANALYTICAL RESULTS WITH THREE OF THE MODIFIED AC ADAPTERS

\begin{tabular}{r|c|c|c} 
Iin (A) & 0.127 & $\operatorname{Pin}(\mathbf{W})$ & 76.2 \\
\hline Vout (V) & 12.8 & $\operatorname{Pout(W)}$ & 49.65 \\
\hline Flyback & $\mathbf{1}$ & $\mathbf{2}$ & $\mathbf{3}$ \\
\hline Vin (V) & 181 & 208 & 211 \\
\hline Iout (A) & 1.14 & 1.34 & 1.4 \\
\hline \multicolumn{4}{|c}{ Analytical model results } \\
\hline Vin (V) & 190.87 & 203.19 & 206.06 \\
\hline Iout (A) & 1.40 & 1.49 & 1.51
\end{tabular}

\section{B. Using customized Flyback converters}

\section{1) Individual Flyback converter}

As mentioned before, in order to increase the input voltage of each individual Flyback and to increase the range of operation in CCM, also four customized Flyback converters have been developed (Fig. 6 shows one of the four customized Flyback).

One of the key points taken into account during the design was achieving a low cost manufacturing prototype, since this is the goal of any commercial APS. In fact, the estimated price of each of the proposed prototypes (considering materials and $\mathrm{PCB})$ is below $\$ 5$.

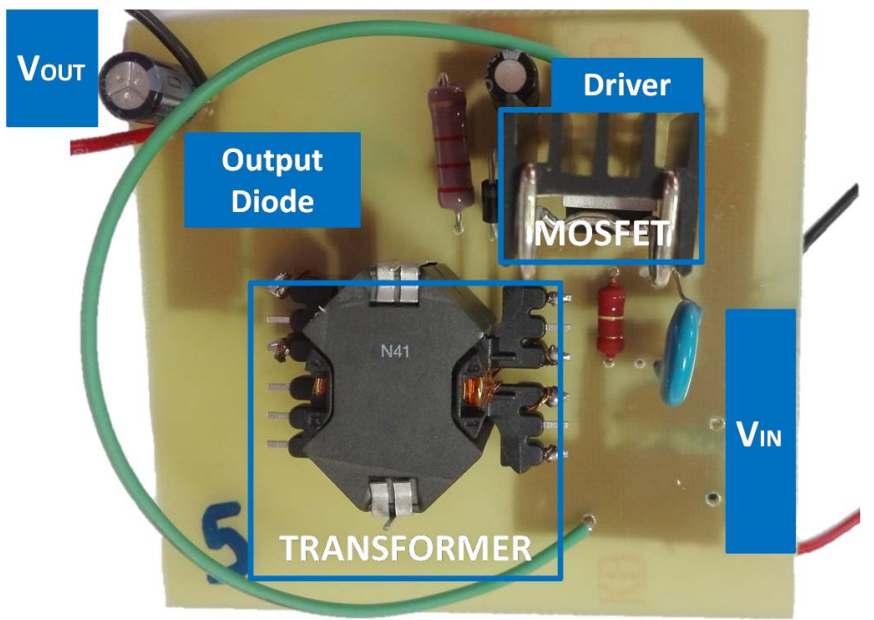

Fig. 6. Customized Flyback prototype developed for higher input voltage

In this case, the current mode standby PWM control IC NCP1271 has been used [25]. This controller allows a fixedfrequency operation of $100 \mathrm{kHz}$ (with some jittering for EMI purposes), as well as, overload, overvoltage, and overtemperature detection, and high voltage start-up. With this controller, a fixed duty cycle $(d)$ can be set, only varying due to the tolerances of the components of the device, itself.

The autonomy of the Flyback converter is mainly provided by the in chip startup circuit implemented in the selected IC. During startup, the supply voltage is provided by the HV pin. This pin is capable of supporting up to $500 \mathrm{~V}$, so it can be connected directly to the input voltage of each cell of the ISOP structure $\left(V_{i n i}\right)$. This pin connects to a current source that charges the decoupling capacitor to its threshold. Once the controller turns on, the transformer auxiliary winding delivers the required charge to the decoupling capacitor and the startup system is turned off.

In the typical application circuit of the IC NCP1271, the duty cycle is usually controlled in closed loop using an optocoupler connected to the FB pin. In the proposed prototype, a feedback loop is not used. The open loop operation is easily implemented connecting a resistor between the FB pin and ground. The value of this resistor will directly determine the fixed duty cycle $(d)$. However, it is also necessary to remove the sense resistor in order to cancel DCM.

Regarding the switch, a 900V / 4A MOSFET has been selected (FQP4N90C of Fairchild [26]). The semiconductor is over-dimensioned in order to withstand possible overdumping when applying input voltages from up to $450 \mathrm{~V}$ together with duty cycles close to $30 \%$. In commercial AC adapters, also similar MOSFETs are used, because no significant differences in cost exist compared with lower voltage semiconductors.

Concerning the transformer, a thorough 3-winding design has been put into practice. For a nominal input voltage of $350 \mathrm{~V}$, output voltage of $15 \mathrm{~V}$, a frequency of $100 \mathrm{kHz}$ and a duty cycle of $30 \%$, the transformer turns ratio must be around 9.9 , and the magnetizing inductance needed must be bigger than $18 \mathrm{mH}$ in order to guarantee CCM operation. 
The main effort in the design of the transformer is put in increasing the range of CCM operation of the Flyback converter. As has been previously mentioned, the CCM operation has to be maintained to keep the output voltage constant for a given input voltage and a given duty cycle. The transformer has been designed to keep the CCM operation for loads as low as $3 \mathrm{~W}$. If it is needed to guarantee the CCM operation for lower loads, even for open circuit operation, a minimum load that ensures a consumption of $3 \mathrm{~W}$ should be used.

A RM10 and N41 core material were selected, together with a six-layer interleaved configuration among windings, to achieve a good relation among leakage and magnetizing inductances, as well as, low resistance and mutual capacitance values, without increasing the size of the component.

Once each Flyback is developed, they are fully tested to validate their proper operation. All the Flyback converters have been developed as similar as possible, but due to tolerances in the components, especially the IC, some differences in the output voltages given by each Flyback is measured. The proper IVS and OCS will be mainly determined by the differences in the parameter $N_{i}$ and consequently in the output voltage of each Flyback when the same input voltage and output power is applied. TABLE IV shows the main parameters of each Flyback converter in a given operation point.

Efficiency is not a key point during the design of the transformer or the selection of components of this converter, since power losses are trifling compared to the power managed in these kind of applications.

TABLE IV. EXPERIMENTAL RESULTS OF EACH CUSTOMIZED FLYBACK WORKING INDEPENDENTLY

\begin{tabular}{r|c|c|c|c}
\multicolumn{6}{c}{ Common operation point } \\
\hline $\mathbf{V}_{\text {in }}(\mathbf{V})$ & 350 & & $\mathbf{R}(\mathbf{\Omega})$ & 30 \\
\hline \multicolumn{5}{|c}{ Particular measurements } \\
\hline Flyback & $\mathbf{1}$ & $\mathbf{2}$ & $\mathbf{3}$ & $\mathbf{4}$ \\
\hline $\mathbf{I}_{\text {in }}(\mathbf{m A} \mathbf{A})$ & 31 & 30 & 33 & 31 \\
\hline $\mathbf{V}_{\text {out }}(\mathbf{V})$ & 15.27 & 15.17 & 15.63 & 15.22 \\
\hline $\mathbf{I}_{\text {out }}(\mathbf{A})$ & 0.518 & 0.515 & 0.531 & 0.517
\end{tabular}

TABLE V. IVS AND OCS EXPERIMENTAL RESULTS WITH FOUR OF THE CUSTOMIZED CONVERTERS

\begin{tabular}{r|c|c|c|c}
$\mathbf{I}_{\text {in }}(\mathbf{m A})$ & 36 & & $\mathbf{P}_{\text {in }}(\mathbf{W})$ & 50.39 \\
\hline $\mathbf{V}_{\text {out }}(\mathbf{V})$ & 14.99 & & $\mathbf{P}_{\text {out }}(\mathbf{W})$ & 37.96 \\
\hline Flyback & $\mathbf{1}$ & $\mathbf{2}$ & $\mathbf{3}$ & $\mathbf{4}$ \\
\hline $\mathbf{V}_{\text {in }}(\mathbf{V})$ & 352.2 & 356.1 & 338 & 353.4 \\
\hline $\mathbf{I}_{\text {out }}(\mathbf{A})$ & 0.642 & 0.651 & 0.6 & 0.639
\end{tabular}

\section{1) Flyback-based ISOP converter}

Using four customized Flyback converters a $1500 \mathrm{~V}$ input voltage Flyback-based ISOP converter is developed and tested in different operation points (input voltages from $1200 \mathrm{~V}$ to
$1500 \mathrm{~V}$ and output power from $35 \mathrm{~W}$ to $55 \mathrm{~W}$ ). As an example, TABLE $V$ shows the input voltage and output current distribution operating with an input voltage of $1400 \mathrm{~V}$ and an output power of $38 \mathrm{~W}$ (these specifications are also used to obtain the simulation results show in TABLE II)In Fig. 7 three different characteristics of the Flyback-based ISOP converter are shown. The startup is captured to verify that there is not important overvoltage at the input of each Flyback converter and the input current is shared, even when each converter starts up and begins to transfer power. In addition, the voltages at the input of three of the four Flyback converters, all of them referred to the same ground, are shown to check a good IVS. Finally, the output voltage is included to validate that it is proportional to the input voltage.

Finally, Fig. 8 shows the voltages at the input of the four Flyback converters, all of them referred to the same ground.

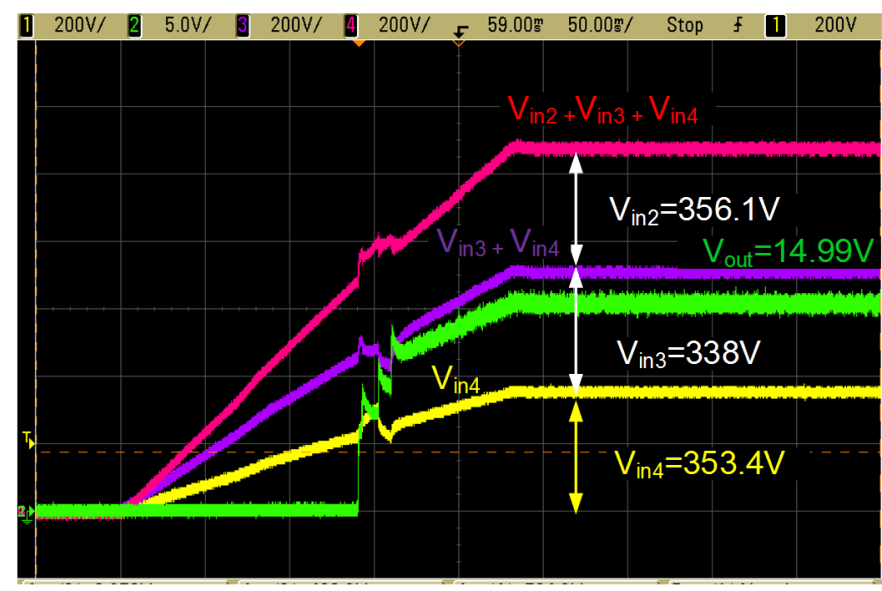

Fig. 7. Experimental waveforms during startup: input voltage distribution and output voltage.

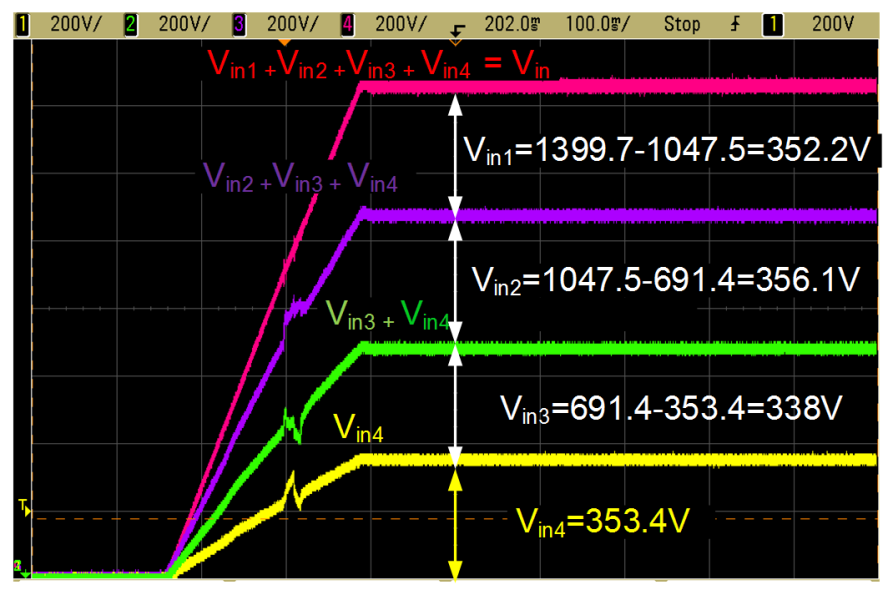

Fig. 8. Experimental waveforms of the input voltage distribution of the four Flyback converters. 


\section{CONCLUSIONS}

An APS intended to feed the cells of a modular SST is presented in this paper. The proposed solution uses a modular ISOP connection of autonomous Flyback converters operating in CCM and in open loop. A modular solution allows the use of the APS in cells with high voltage DC links by increasing the number of Flyback converters.

The validation of the proposed topology and control strategy has been confirmed by simulation and experimental results. The experimental results have been obtained using two different approach. On one hand, a modified commercial AC adapter has been used to develop the Flyback-based ISOP converter to show the flexibility of the topology. On the other hand, a customized Flyback converter was designed to perform the final prototype of a Flyback-based ISOP converter with an input voltage of $1400 \mathrm{~V}$. It was tested to evaluate the IVS and OCS at high voltage.

It has been shown that, assuming a good similarity between all the Flyback converters (mainly in the value of $N$ ) that compose the ISOP configuration, a proper IVS and OCS can be obtained.

\section{ACKNOWLEDGMENT}

This work was carried out by funding from the Government of Spain through projects DPI2013-47176-C2-2-R, MINECO15-DPI2014-56358-JIN and the grant FPI BES-2014-070785, through funding from the Government of Asturias through the project FC-15-GRUPIN14-143 and FEDER funds, and thanks to the project of the European Commission "Silicon Carbide Power Electronics Technology for Energy Efficient Devices", SPEED, FP7 Large Project (NMP3-LA-2013-604057).

\section{REFERENCES}

[1] Jianjiang Shi; Wei Gou; Hao Yuan; Tiefu Zhao; Huang, A.Q., "Research on voltage and power balance control for cascaded modular solid-state transformer," Power Electronics, IEEE Transactions on, vol.26, no.4, pp.1154,1166, April 2011

[2] Ronan, E.R.; Sudhoff, S.D.; Glover, S.F.; Galloway, D.L., "A power electronic-based distribution transformer," in Power Delivery, IEEE Transactions on , vol.17, no.2, pp.537-543, Apr 2002

[3] van der Merwe, J.W.; du T. Mouton, H.; , "The solid-state transformer concept: A new era in power distribution," AFRICON, 2009. AFRICON '09. , vol., no., pp.1-6, 23-25 Sept. 2009

[4] Jih-Sheng Lai; Maitra, A.; Mansoor, A.; Goodman, F.; , "Multilevel intelligent universal transformer for medium voltage applications," Industry Applications Conference, 2005. Fourtieth IAS Annual Meeting. Conference Record of the 2005 , vol.3, no., pp. 1893- 1899 Vol. 3, 2-6 Oct. 2005

[5] Xu She; Huang, A., "Solid state transformer in the future smart electrical system," in Power and Energy Society General Meeting (PES), 2013 IEEE , vol., no., pp.1-5, 21-25 July 2013

[6] W. McMurray, "Power converter circuits having a high-frequency link," U.S. Patent 3517300, June 23, 1970

[7] Shojaei, A.; Joos, G., "A modular solid state transformer with a singlephase medium-frequency transformer," Electrical Power \& Energy Conference (EPEC), 2013 IEEE, pp.1, 5, 21-23 Aug. 2013

[8] DeDoncker, R. W.; Divan, R. W.; Kheraluwala, M.H., "A three-phase soft-switched high power-density dc/dc converter for high -power applications". IEEE Transactions on Industry Applications, vol. 27, p. 6373. January 1991.
[9] Kheraluwala, M. H.; Gascoigne, R. W.; Divan, D. M.; Baumann, E.D., "Performance characterization of a high-power dual active bridge dc-todc converter". IEEE Transactions on Industry Applications, vol. 28, p. 1294-1301. November 1992.

[10] Rodríguez, A.; Sebastian, J.; Lamar, D.G.; Hernando, M.M.; Vazquez, A., "An overall study of a Dual Active Bridge for bidirectional DC/DC conversion". IEEE Energy Conversion Congress and Exposition (ECCE), p. 1129-1135. September 2010.

[11] Rodriguez, A.; Vazquez, A.; Lamar, D.G.; Hernando, M.M.; Sebastian, J., "Different Purpose Design Strategies and Techniques to Improve the Performance of a Dual Active Bridge With Phase-Shift Control," Power Electronics, IEEE Transactions on , vol.30, no.2, pp.790,804, Feb. 2015

[12] Fernando Briz, Mario Lopez, Alberto Zapico, Alberto Rodriguez, David Diaz-Reigosa, "Operation and Control of MMCs Using Cells with Power Transfer Capability," 30th Annual IEEE Applied Power Electronics Conference \& Exposition (APEC), 15-19 March 2015, Charlotte, NC, USA

[13] M. López, A. Rodríguez, E. Blanco, M. Saeed, Á. Martínez, F. Briz, "Design and Implementation of the Control of a MMC Based Solid State Transformer," IEEE International Conference on Industrial Informatics INDIN'15, 22-24 July 2015, Cambridge, UK

[14] Vechalapu, K.; Bhattacharya, S.; Van Brunt, E.; Sei-Hyung Ryu; Grider, D.; Palmour, J.W., "Comparative evaluation of $15 \mathrm{kV} \mathrm{SiC} \mathrm{MOSFET} \mathrm{and}$ $15 \mathrm{kV} \mathrm{SiC} \mathrm{IGBT} \mathrm{for} \mathrm{medium} \mathrm{voltage} \mathrm{converter} \mathrm{under} \mathrm{same} \mathrm{dv} / \mathrm{dt}$ conditions," in Energy Conversion Congress and Exposition (ECCE), 2015 IEEE, pp.927-934, 20-24 Sept. 2015

[15] "Silicon Carbide Power Technology for Energy Efficient Devices (SPEED)", Ref. FP7-NMP3-LA-2013-604057, EU - FP7, Large Scale Integrating Collaborative Research Project.

[16] Xinbo Ruan; Wu Chen; Lulu Cheng; Tse, C.K.; Hong Yan; Tao Zhang, "Control Strategy for Input-Series-Output-Parallel Converters,"Industrial Electronics, IEEE Transactions on, vol.56, no.4, pp.1174,1185, April 2009

[17] Kadavelugu, A.; Wang, G.; Bhattacharya, S.; Huang, A., "Auxiliary power supply for Solid State Transformers," Energy Conversion Congress and Exposition (ECCE), 2012 IEEE, pp.1426-1432, 15-20 Sept. 2012.

[18] Il-Oun Lee; Gun-Woo Moon, "Analysis and Design of a Three-Level LLC Series Resonant Converter for High- and Wide-Input-Voltage Applications," Power Electronics, IEEE Transactions on , vol.27, no.6, pp.2966-2979, June 2012.

[19] T. Song, N. Huang, A. Ioinovici, "A family of zero-voltage and zerocurrent-switching (ZVZCS) three-level DC-DC converters with secondary-assisted regenerative passive snubber," IEEE Trans. Circuits Syst. I, Reg. Papers, vol. 52, no.11, pp. 2473-2481, Nov. 2005.

[20] Wu Chen; Kai Zhuang; Xinbo Ruan, "A Input-Series- and OutputParallel-Connected Inverter System for High-Input-Voltage Applications," Power Electronics, IEEE Transactions on, vol.24, no.9, pp.2127-2137, Sept. 2009.

[21] P. Grbovic, "Master/Slave Control of Input-Series- and OutputParallelConnected Converters: Concept for Low-Cost High-Voltage Auxiliary Power Supplies," IEEE Transactions on Power Electron., vol. 24, No. 2, pp. 316-328, Feb. 2009.

[22] Sheng Zong; Qianlai Zhu; Yu Wensong; Huang, A.Q., "Auxiliary power supply for solid state transformer with ultra high voltage capacitive driving," Applied Power Electronics Conference and Exposition (APEC), 2015 IEEE, vol., no., pp.1008,1013, 15-19 March 2015

[23] R. W. Erickson and D. Maksimovic, "Fundamentals of Power Electronics", 2nd ed. New York, NY, USA: Springer Science+Business Media, LLc, 2001.

[24] https://www.we-online.com/

[25] http://www.onsemi.com/pub link/Collateral/NCP1271-D.PDF last visit $22 / 06 / 2016$.

[26] https://www.fairchildsemi.com/datasheets/FQ/FQP4N90C.pdf last visit $22 / 06 / 2016$ 